\title{
Noise and Room Acoustic Conditions in a Tertiary Referral Hospital, Seoul National University Hospital
}

\author{
Wan-Ho Cho' ${ }^{1}$, Cheol-Ho Jeong ${ }^{2}$, Ji-Ho Chang ${ }^{1}$, Seong-Hyun Lee ${ }^{3}$, \\ Moo Kyun Park', Myung-Whan Suh', and Jae Joon $\mathrm{Han}^{4}$ \\ ${ }^{1}$ Division of Physical Metrology, Korea Research Institute of Standards and Science, Daejeon, Korea \\ ${ }^{2}$ Acoustic Technology, Electrical Engineering Department, Technical University of Denmark, Lyngby, Denmark \\ ${ }^{3}$ Department of System Dynamics, Korea Institute of Machinery \& Materials, Daejeon, Korea \\ ${ }^{4}$ Department of Otorhinolaryngology-Head and Neck Surgery, Seoul National University Hospital, Seoul, Korea
}

\section{Received June 7, 2018 \\ Revised September 3, 2018 \\ Accepted October 17, 2018}

\section{Address for correspondence}

Ji-Ho Chang, PhD

Division of Physical Metrology,

Korea Research Institute

of Standards and Science,

267 Gajeong-ro, Yuseong-gu,

Daejeon 34113, Korea

Tel +82-42-868-5309

Fax +82-42-868-5643

E-mail jiho.chang@kriss.re.kr

This study has been presented in part in Baltic-Nordic Acoustics Meeting 2018.
Background and Objectives: Noise levels and room acoustic parameters at a tertiary referral hospital, Seoul National University Hospital (SNUH) in Korea, are investigated. Materials and Methods: Through a questionnaire, acoustically problematic rooms are identified. Noise levels in emergency rooms (ERs) and intensive care units (ICUs) are measured over about three days. Acoustically critical and problematic rooms in the otolaryngology department are measured including examination rooms, operating rooms, nurse stations, receptions, and patient rooms. Results: The A-weighted equivalent noise level, $L_{\text {Aeq, }}$ ranges from 54 to $56 \mathrm{dBA}$, which is at least $10 \mathrm{~dB}$ lower than the noise levels of 65 to $73 \mathrm{dBA}$ measured in American ERs. In an ICU, the noise level for the first night was $66 \mathrm{dBA}$, which came down to $56 \mathrm{dBA}$ for the next day. The noise levels during three different ear surgeries vary from 57 to $62 \mathrm{dBA}$, depending on the use of surgical drills and suctions. The noise levels in a patient room is found to be $47 \mathrm{dBA}$, while the nurse stations and the receptions have high noise levels up to $64 \mathrm{dBA}$. The reverberation times in an operation room, examination room, and single patient room are found to be below $0.6 \mathrm{~s}$. Conclusions: At SNUH, the nurse stations and receptions were found to be quite noisy. The ERs were quieter than in the previous studies. The measured reverberation times seemed low enough but some other nurse stations and examination rooms were not satisfactory according to the questionnaire.

J Audiol Otol 2019;23(2):76-82

KEY WORDS: Hospital noise · ER noise $\cdot$ ICU noise $\cdot$ Ear surgery noise $\cdot$ Reverberation time.

\section{Introduction}

Hospitals, in general, are known to be not quiet according to various studies, see for examples [1-24]. No results satisfied the World Health Organization guidelines for community noise of $35 \mathrm{dBA}$ as (A-weighted equivalent sound pressure level) $\mathrm{L}_{\text {Aeq, }}$, which happens to be the noise limit for hospital rooms where patients are treated and observed [25]. Acoustically most interesting rooms in hospitals are two-

This is an Open Access article distributed under the terms of the Creative Commons Attribution Non-Commercial License (https://creativecommons.org/licenses/by-nc/4.0/) which permits unrestricted non-commercial use, distribution, and reproduction in any medium, provided the original work is properly cited. fold: rooms where patients need good quality tranquility to focus on healing and rooms where staff needs concentration. Reverberation characteristics influence verbal communication between patients and staff. There is no building legislation for Korean hospitals in terms of reverberation time, but other countries have building regulations, e.g., Danish Building Regulation (BR18) setting a maximum reverberation time of $0.6 \mathrm{~s}$ for examination rooms and patient bedrooms in the frequency range of $125-4,000 \mathrm{~Hz}$ [26]. As the medical care is absolutely prioritized, hospitals tend to underestimate the importance of acoustics.

In this study, noise levels were measured in emergency rooms (ERs) and intensive care units (ICUs) in Seoul Na- 
tional University Hospital (SNUH), a tertiary referral hospital in Seoul, Korea, for four days in 2017. In addition, examination rooms, operating rooms, and patient rooms in the otolaryngology department were measured as these rooms are considered acoustically critical. Nurse stations and receptions were found to be noisy and therefore measured. Noise levels were measured in all the abovementioned rooms, and the reverberation time was measured in an operation room, an examination room, and a patient room. A questionnaire survey was conducted to figure out acoustically problematic rooms and noise sources.

In the literature, there have been many investigations on noise levels in ICUs [1-13], in ERs [13-17], and in operating rooms including surgical drill noise [18-24]. Individual noise sources were analyzed in $[5,10]$, and some attempted to reduce the hospital noise [27,28]. Only one study measured noise in a Korean hospital, but these measurements were limited to patient rooms, mainly focusing on sleep disturbance [2]. The present study measured the noise levels and reverberation times in various rooms at SNUH. This is the first attempt to evaluate the hospital soundscape thoroughly at a Korean tertiary referral hospital to the best of the authors' knowledge.

\section{Materials and Methods}

\section{Questionnaire survey}

First, a questionnaire was distributed throughout the hospital in late November 2017, a month prior to the measurement campaign. Many answers were collected from staffs in the Otorhinolaryngology department. The questionnaire basically asked to rank the noise sources, and how severe the noise and acoustics-related problems (mostly about reverberation) are. The noisiest room and the worst room in terms of room acoustics were asked and rated on a 5-point scale. In total, 45 answers were collected.

\section{Measurements}

The measurement was performed in late December 2017. We used three B\&K 2270 (Bruel and Kjaer, Naerum, Denmark) and four LD 831c machines (Larson Davis, Depew,

Table 1. Summary of the noise level in SNUH

\begin{tabular}{|c|c|c|c|c|}
\hline Room & Index & Measurement duration (hours) & $\mathrm{L}_{\text {Aeq }}(\mathrm{dBA})$ & Remark \\
\hline \multirow[t]{3}{*}{ ER - Triage } & 1 & 22 & 55.6 & - \\
\hline & 2 & 21 & 55.7 & \\
\hline & 3 & 22 & 55.6 & \\
\hline \multirow[t]{3}{*}{ ER - Treatment } & 1 & 22 & 54.5 & - \\
\hline & 2 & 21 & 53.9 & \\
\hline & 3 & 22 & 52.4 & \\
\hline \multirow[t]{2}{*}{$\mathrm{ICU}$} & 1 & 22 & 65.7 & Critical patient (CPR) \\
\hline & 2 & 15 & 56.2 & \\
\hline \multirow[t]{4}{*}{ Operating room } & 1 & 2 & 59.3 & Small drill and suction \\
\hline & 2 & 2 & 62.5 & Large drill and suction \\
\hline & 3 & 22 & 57.4 & Suction (without drill) \\
\hline & 4 & 0.1 & 49.2 & Background noise \\
\hline Examination room & 1 & 2 & $55-65$ & - \\
\hline \multirow[t]{6}{*}{ Nurse station } & 1 & 0.5 & 58.0 & Nurse station near patient ward \\
\hline & 2 & 0.5 & 64.1 & Reception area in nurse station \\
\hline & 3 & 0.3 & 61.5 & Preparation room, sterilizer off \\
\hline & 4 & 0.1 & 62.4 & Preparation room, sterilizer on \\
\hline & 5 & 0.5 & 61.5 & Open waiting area, children hospital \\
\hline & 6 & 0.2 & 62.2 & Open waiting area, children hospital 2 \\
\hline \multirow[t]{4}{*}{ Reception } & 1 & 0.2 & 56.6 & Reception, otorhinolaryngology \\
\hline & 2 & 0.5 & 63.7 & Reception, internal medicine \\
\hline & 3 & 0.2 & 62.2 & Reception, children hospital \\
\hline & 4 & 0.2 & 67.0 & Main reception \\
\hline \multirow[t]{3}{*}{ Patient room } & Single & 0.3 & 37 & Unoccupied, door \& window closed \\
\hline & Single & 0.3 & 50 & Unoccupied, window open/door closed \\
\hline & Multiple & 0.2 & 47 & Occupied, door open/window closed \\
\hline
\end{tabular}

SNUH: Seoul National University Hospital, ER: emergency room, ICU: intensive care unit, CPR: cardiopulmonary resuscitation, LAeq: A-weighted equivalent sound pressure level 
NY, USA). A B\&K Dirac system (type 7841) with a B\&K 4130 microphone and a B\&K 4292 omni-directional source was used for room acoustic measurement according to ISO 33822 [29]. Measurement places and durations can be found in Table 1.

In ERs and ICUs, sound level meters were installed with logging function on for three days. In ERs (Fig. 1A and B), two sound level meters were installed: one in a triage area (Fig. 1B), and the other in a treatment room. The former one was installed at a safe place close to the ceiling so that no one could easily touch. The latter one was installed near a patient bed, which happened to be close to the nurse station. Even if these locations might not be the best spots in this ER section, the most important consideration in determining the measurement spot was security and safety of the sound level meter, meaning that nobody accidentally touches or stops it by any means. In addition, the measurements should not disturb working paths between the patients and nurses. Ideally, hanging the microphone from the ceiling could be an option, but it was not possible in this hospital due to a particular gypsum panel ceiling installation. At a surgical ICU (Fig. 1C and D), a sound level meter was installed on a shelf between a patient bed and a window because this place is also unlikely that people easily touch, or staff is disturbed.

In other rooms, we measured noise and reverberation characteristics for less than an hour at each measurement position. At an operating room (Fig. 2A), background noise level, noise levels during three ear surgeries, and early decay time (EDT) were measured. The dimensions were $5.8 \mathrm{~m} \times 9.4 \mathrm{~m} \times$ $3.5 \mathrm{~m}(\mathrm{H})$. At an examination room (Fig. 2B), the background noise, noise during examinations, and the reverberation time $\left(\mathrm{T}_{20}\right)$ were measured. The examination rooms in the Otorhinolaryngology department were similar in dimensions of $3.5 \mathrm{~m} \times 4.0 \mathrm{~m} \times 3.0 \mathrm{~m}(\mathrm{H})$, in shape as rectangular, and in distribution of furniture and medical devices. There were three booths for audiometry and auditory brainstem response measurements, where the background noise and the reverberation time $\left(\mathrm{T}_{20}\right)$ were measured. The dimensions were $2.3 \mathrm{~m} \times 2.0$ $\mathrm{m} \times 2.0 \mathrm{~m}(\mathrm{H}), 1.9 \mathrm{~m} \times 1.8 \mathrm{~m} \times 2.0 \mathrm{~m}(\mathrm{H})$, and $1.9 \mathrm{~m} \times 1.5 \mathrm{~m} \times 2.0$ $\mathrm{m}(\mathrm{H})$, respectively.

The noise levels at 6 nurse stations (Fig. 2C and D) and 4 reception areas (Fig. 3A and B) were measured. Various places were chosen for these measurements (Table 1). The noise levels in two different patients' rooms were also measured. One was a single patient room (Fig. 3C), where the background noise level and the reverberation time were measured in an empty state. The other was a large room for 8 patients (Fig. $3 \mathrm{D}$ ), and only the noise level with in an occupied state was measured.

Note that some reverberation time measurements did not completely comply with ISO 3382 precision method [21] mainly due to the limited time permitted and small room size. For the same reason, $\mathrm{T}_{20}$ was chosen to be reported with some exceptions of EDTs at lower frequencies of 125 and $250 \mathrm{~Hz}$.
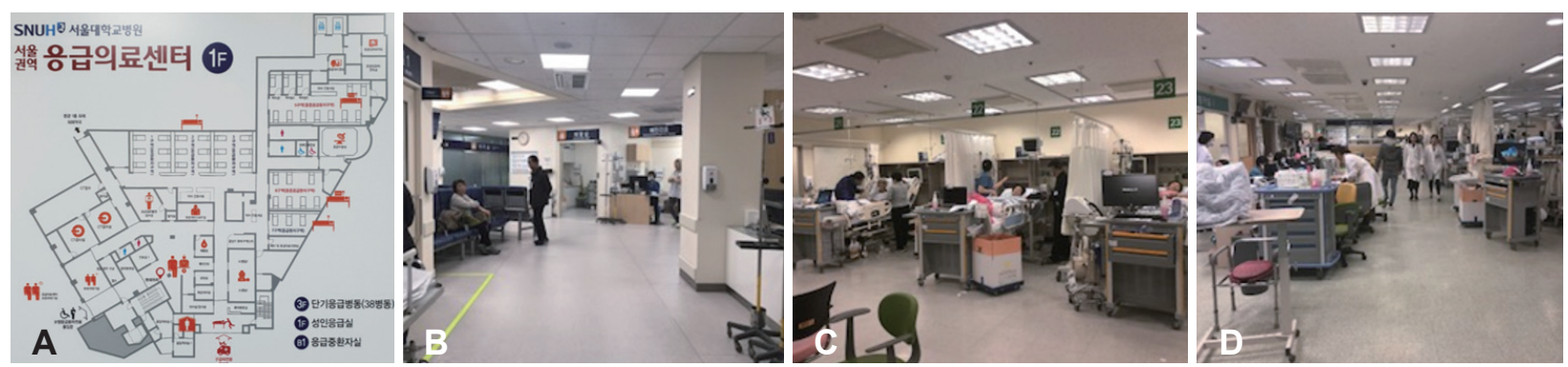

Fig. 1. Photos of ERs (A: sectional plan, B: a triage area) and ICUs (C: a treatment area, D: corriodor). ER: emergency room, ICUs: intensive care units.
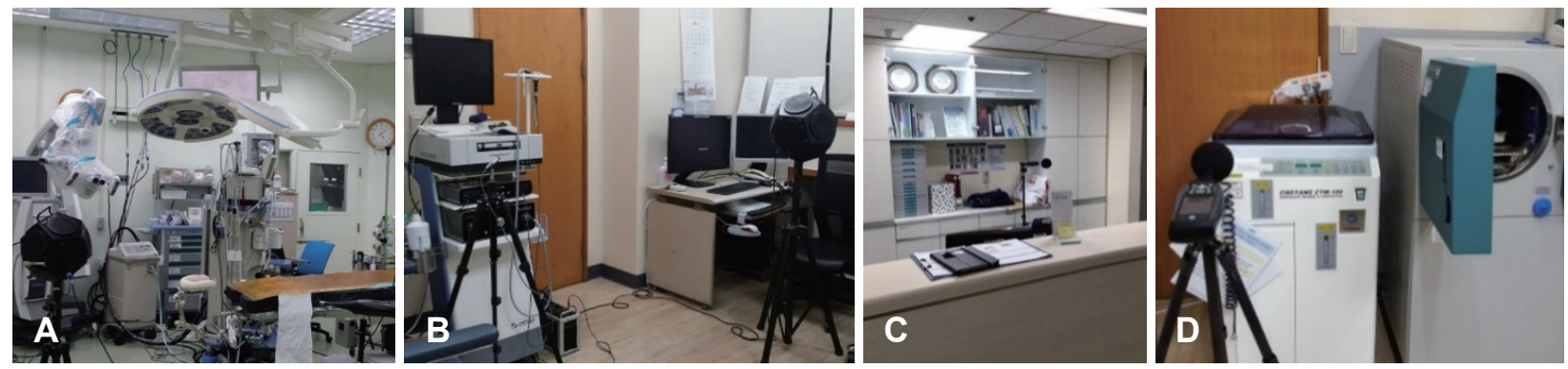

Fig. 2. Photos of (A) operating room, (B) examination room, and the nurse station (C: near patient rooms, D: preparation room).

78 J Audiol Otol 2019;23(2):76-82 

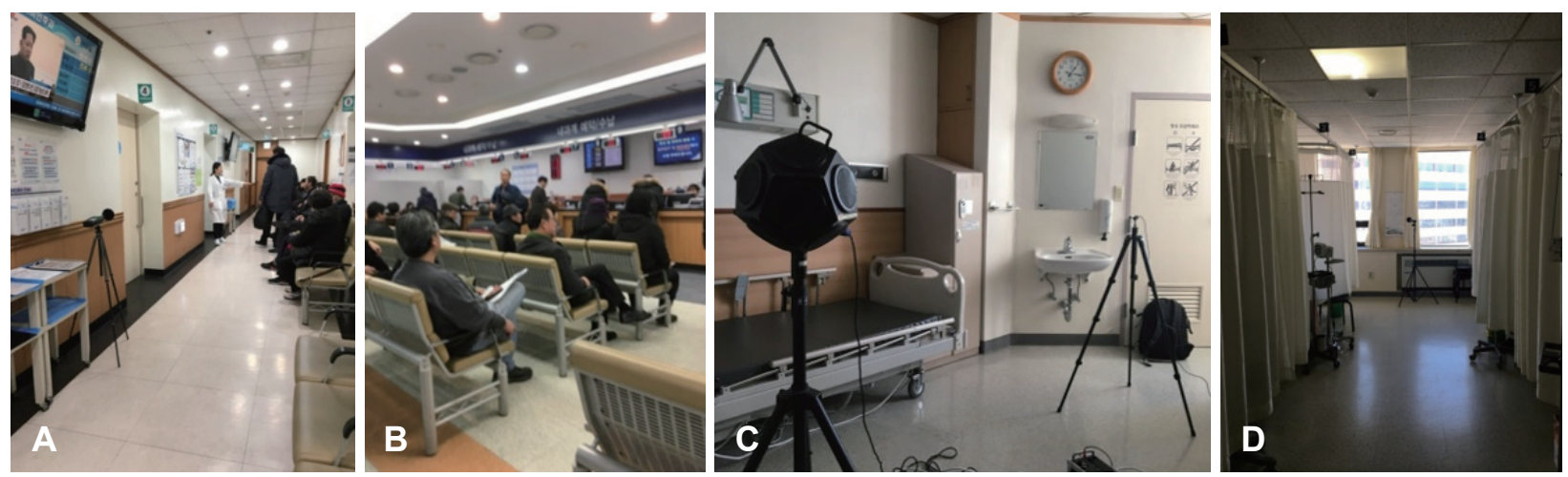

Fig. 3. Photos of reception/waiting area (A: otorhinolaryngology, B: main reception) and patient rooms (C: single patient room, D: 6 patient room).
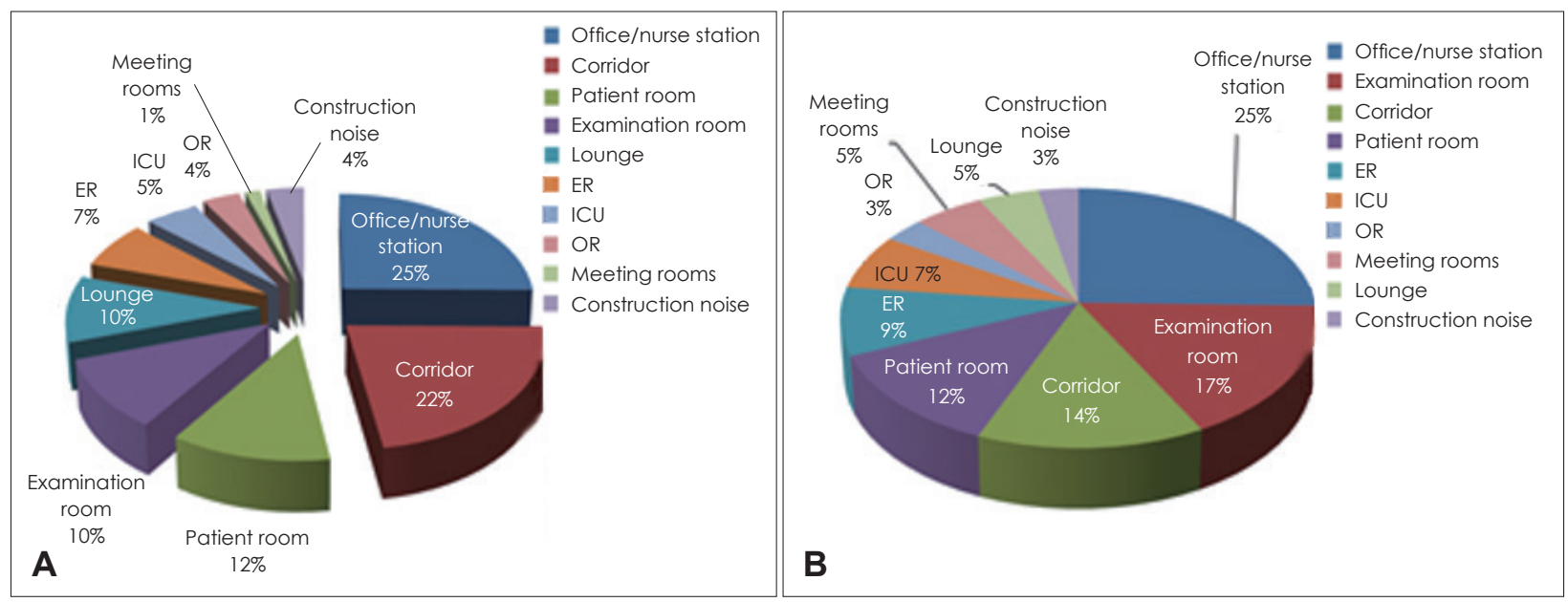

Fig. 4. Room rankings from the questionnaire: $(A)$ noisy rooms and $(B)$ rooms with bad acoustic conditions. ER: emergency room, ICU: intensive care unit, OR: operating room, $L_{\text {Aeq }}$ : A-weighted equivalent sound pressure level.

\section{Results}

\section{Questionnaire survey}

The noisy room rankings are shown in Fig. 4A, and the most problematic rooms in terms of room acoustics are shown in Fig. 4B. The mean rating regarding noise was 2.2 on a five-point scale, 1 being "not at all disturbing" to 5 being "extremely noisy." The noisiest room was answered to be office/ nurse stations, followed by corridors, patient rooms, and examination rooms. On the other hand, the mean rating for bad acoustics was 2.0, which is equivalent to 'slightly disturbed.' Office/nurse stations are again rated worst in terms of acoustics, followed by examination rooms and corridors.

Fig. 5 shows the main noise sources, indicating medical devices, external noise, and talking sound were annoying. The external noise could imply traffic noise and other types of noise, but here it mostly means construction noise due to an underground expansion of the hospital at the time of questionnaire. During the measurement, this construction noise was noticeably reduced according to the hospital staff.

\section{Noise levels}

Table 1 shows the noise levels in SNUH. At the triage section of ER, $\mathrm{L}_{\text {Aeq }}$ was $55.6 \mathrm{dBA}$ over the first 22 hours, 55.7 $\mathrm{dBA}$ over the next 21 hours, and $55.6 \mathrm{dBA}$ for the rest 22 hours. The noise level in the treatment ER was measured to be 54.5, 53.9, and 52.4 dBA for the same time intervals, respectively. The noise level did not vary too much over the three days, so it could be regarded to be representing the noise level in the ER. The time history is shown in Fig. 6.

In the surgical ICU, we observed quite different noise levels for two days. For the first 22 hours, the noise level was quite high as $65.7 \mathrm{dBA}$, with several intervals with $\mathrm{L}_{\text {Cpeak }}$ of $112.4 \mathrm{dBC}$. Next day a nurse answered that there was a critical patient, so the alarm rings constantly and cardiopulmonary resuscitation was conducted by the medical team. For the next 15 hours, the noise level went down to $56.2 \mathrm{dBA}$. Unfortunately, the third day data were lost for unknown reasons. Fig. 7 shows the time history.

In the operating room, the first noise measurement was conducted during an implantation surgery of cochlear pros- 


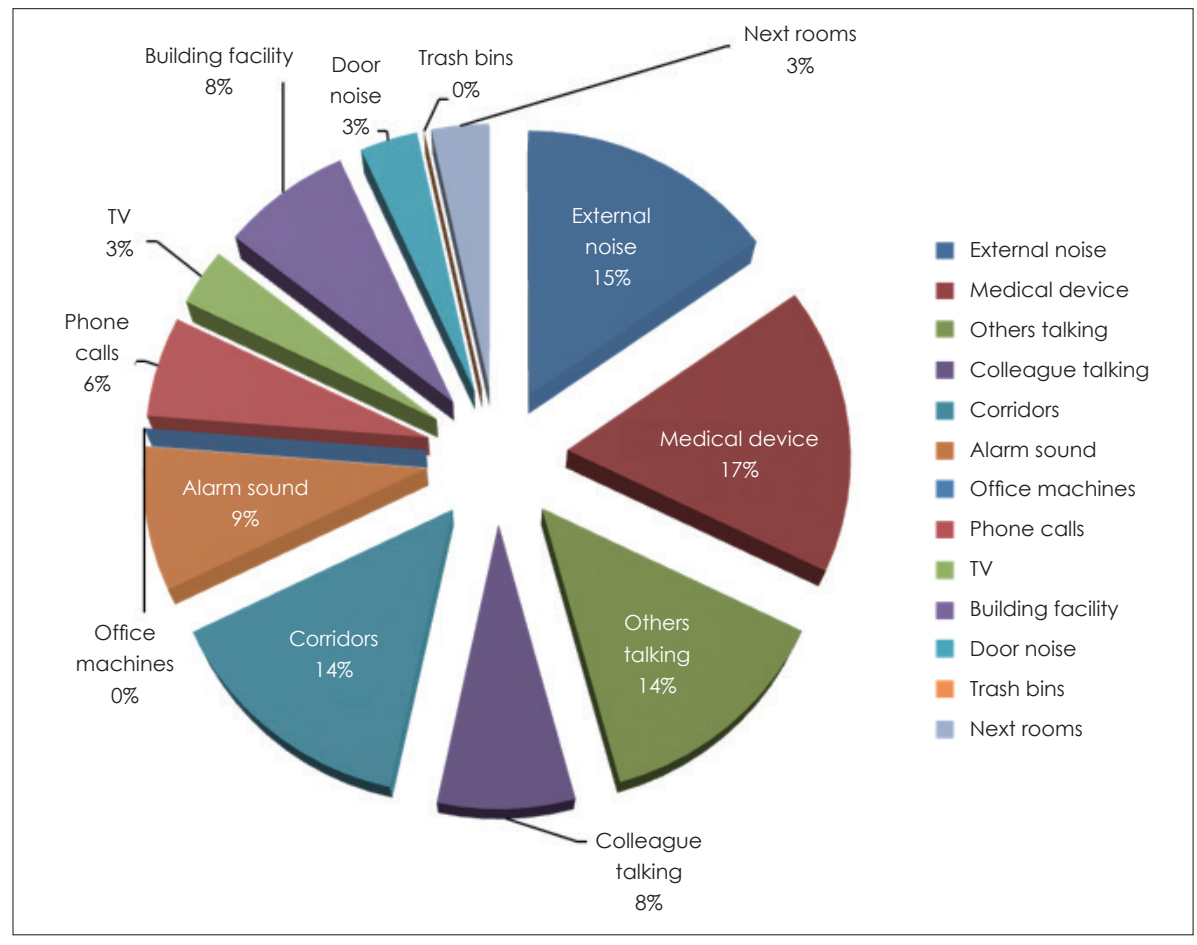

Fig. 5. Main noise source ranking.

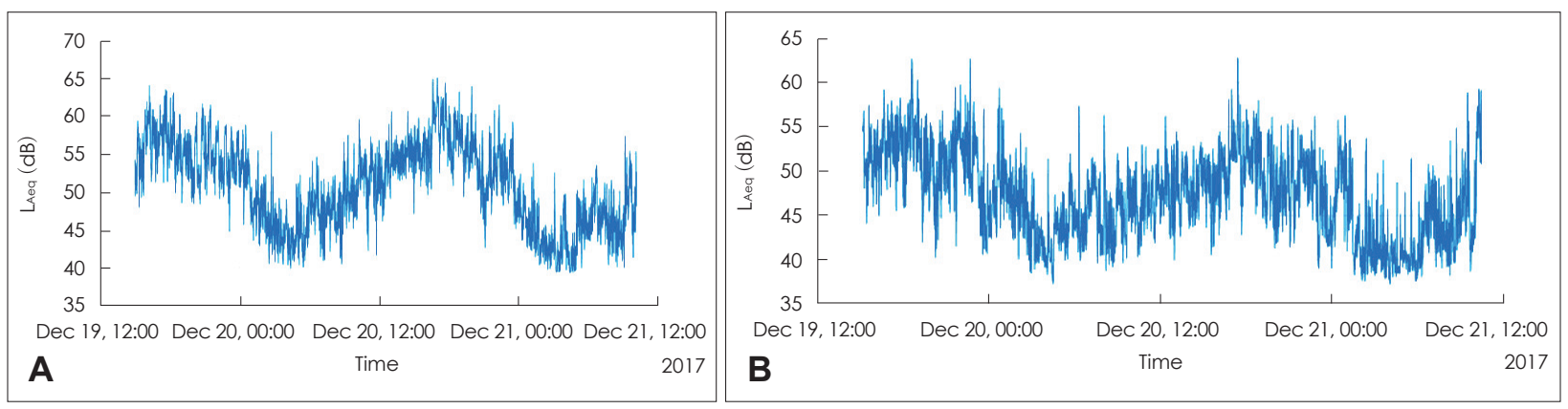

Fig. 6. Time history of the measured noise level $\left(\mathrm{L}_{\mathrm{Aeq}}\right)$ at the ER of SNUH: $(A)$ triage section, $(B)$ treatment ER. SNUH: Seoul National University Hospital, ER: emergency room, LAeq: A-weighted equivalent sound pressure level

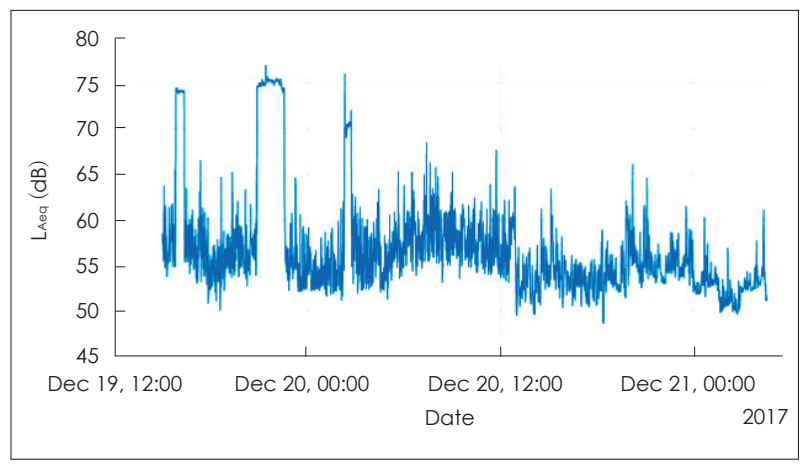

Fig. 7. Time history of the measured noise level $\left(L_{\text {Aeq }}\right)$ at the ICU. ICU: intensive care unit.

thetic device, which was known to be relatively noisy due to surgical drills and suctions. The measurement started after changing to small drills (posterior tympanotomy), and it was $59.3 \mathrm{dBA}$. The second surgery was a canal wall down mas- toidectomy, where large drills and suctions were used, and the average noise level was $62.5 \mathrm{dBA}$. Lastly, an intact canal wall mastoidectomy was measured, which was regarded as a quiet surgery. Particularly, the measurement started after drilling, so the noise level was lowest as $57.4 \mathrm{dBA}$. In summary, the main noise sources in these three surgeries were small drills, large drills, and suctions with noise levels of 59.3, 62.5, and $57.4 \mathrm{dBA}$, respectively. The background noise was measured to be $49.2 \mathrm{dBA}$.

In the examination room, the noise from medical devices varied between 55 to $65 \mathrm{dBA}$ during examinations. The sound transmission between the examination rooms was not measured but one could hear noise from the adjacent examination room. The background noise including the construction heating, ventilation, and air conditioning noise was $49.6 \mathrm{dBA}$, which is as high as in the operating room. 
Table 2. Summary of the reverberation time in SNUH

\begin{tabular}{ccccccc}
\hline Room (s) & $125 \mathrm{~Hz}$ & $250 \mathrm{~Hz}$ & $500 \mathrm{~Hz}$ & $1 \mathrm{kHz}$ & $2 \mathrm{kHz}$ & $4 \mathrm{kHz}$ \\
\hline Operating room, EDT & 0.48 & 0.58 & 0.53 & 0.56 & 0.55 & 0.44 \\
Examination room, $\mathrm{T}_{20}$ & 0.50 & 0.43 & 0.40 & 0.37 & 0.32 & 0.29 \\
Patient room-Single, $\mathrm{T}_{20}$ & 0.40 & 0.33 & 0.31 & 0.33 & 0.30 & 0.25 \\
\hline
\end{tabular}

SNUH: Seoul National University Hospital, EDT: early decay time

The nurse station was pointed out by the staff to be noisiest in the questionnaire in Fig. 4. The measurement confirmed this statement; the noise level at the nurse station ranged 58$64 \mathrm{dBA}$ in several measurements near wards, examination rooms, and children department, which was even noisier than in ERs. The highest level measured was $64.1 \mathrm{dBA}$ at a nurse station that also functions as a reception (Fig. 2C), and the second highest value, $62.4 \mathrm{dBA}$ was measured at a preparation room when a sterilizer is running (Fig. 2D). Except for these values, the noise level ranged 58.0-62.2 dBA.

The noise levels at receptions ranged 56-67 dBA. The most crowded reception (Fig. 3B) had a value of $67.0 \mathrm{dBA}$, which was the highest noise level measured in this study. But receptions were not ranked as a noisy or acoustically problematic room in the questionnaire. A likely reason could be that many receptions are located in corridor areas, which were ranked as the second noisiest and the third worst rooms acoustically (Fig. 4).

In the single patient room, the background noise level with all doors and windows closed was $37 \mathrm{dBA}$. With the windows open, the background noise level went up to $50 \mathrm{dBA}$ due to the construction noise outside the building although the room was unoccupied. In the 6 patient room, with 8 people in an occupied state, $\mathrm{L}_{\text {Aeq }}$ was $47 \mathrm{dBA}$, which was regarded surprisingly quiet.

\section{Reverberation time}

Table 2 shows the reverberation times. In the operating room, the spatially averaged EDT over 5 measurement positions was lower than $0.6 \mathrm{~s}$ from the $125 \mathrm{~Hz}$ to $4 \mathrm{kHz}$ octave bands. At the examination room, the reverberation time $\mathrm{T}_{20}$ in an empty condition was measured to be lower than $0.5 \mathrm{~s}$. In the single patient room, the reverberation time $\mathrm{T}_{20}$ was measured to be reasonably low as indicated in Table 2 .

\section{Discussion}

The noise level in the ICU at SNUH ranges from 56.2 to $65.7 \mathrm{dBA}$. These values are not different from what has been reported in previous studies [1-13]. For example, the noise levels measured close to patients in an ICU in the UK are all higher than $54 \mathrm{dBA}$ [5], and the level in Jeroen Bosch hospi- tal, the Netherlands, is $61 \mathrm{dBA}$ [4]. The background noise level in the operating room was also as high as those measured in the previous studies [18-24]. Noise by surgical drills and suctions in the operating room, 57.4, 59.3, and 62.5 dBA, were much lower than the values in [24] reported 40 years ago. This difference can be due to improved surgical devices over recent decades.

The noise levels measured in ERs, 52 to $56 \mathrm{dBA}$, were quite lower than in most previous studies. $\mathrm{L}_{\text {Aeq }}$ in the emergency department of Johns Hopkins hospital ranges from 65 to $73 \mathrm{dBA}$ [6], which is at least $10 \mathrm{~dB}$ higher than in SNUH. This is possibly due to the cultural aspect and new refurbishment. The entire emergency department at SNUH was refurbished throughout 2017, to have a triage area in the middle, being connected to several small treatment rooms with a small number of beds as shown in Fig. 1A. The main reason for the refurbishment was to prevent the spread of contagious disease, such as Middle East respiratory syndrome. The medical staff mentioned that overall noise level in ERs has been reduced after the refurbishment. Recent measurements in Danish hospitals for 4-5 days shows 56 to $58 \mathrm{dBA}$ [30], and these values are as low as the measured value in the present study.

The Danish Building Regulation (BR18) sets a maximum reverberation time of $0.6 \mathrm{~s}$ for examination rooms and patient bedrooms in the frequency range of $125-4,000 \mathrm{~Hz}$ [26]. Although this recommendation does not apply in Korea, the reverberation time measured in the examination and patient wards in SNUH seems satisfactory.

In conclusion, noise levels and room acoustic parameters were measured at SNUH. Noise levels were measured in ERs, ICUs, examination rooms, operating rooms, nurse stations, receptions, and patient rooms. Room acoustic parameters, e.g., T_20 and EDT, were measured in an operation room, examination room, and single patient room.

Although the ERs were quieter than those in other previous studies, it was anyway impossible to achieve the WHO guideline. The noise levels at the nurse stations and reception areas were quite high, which concurs with the questionnaire answers. These places need an urgent improvement.

All the reverberation times measured at SNUH were quite low, complying with the Danish building regulation, BR18. However, according to the questionnaire, some nurse stations 
and examination rooms have acoustical problems that should be identified and fixed properly.

\section{Acknowledgments}

The authors are grateful to Prof. Seung-Ha Oh, the chairman of department of Otorhinolaryngology, SNUH, for arranging the measurement at the hospital and Dr. Jae-Gab Suh at KRISS and Dr. SangYeob Lee at SNUH for assistance with the measurements. A big thanks goes to Prof. Jeong-Guon Ih and Mr. In-Jee Jung at KAIST for lending/preparing the equipment and further fruitful comments. We also thank Dr. Woo-Keun Song and Mr. Moon-Ju Hwang at B\&K for lending the 2270 equipment. Finally, the comments from Dr. PyoungJik Lee from University of Liverpool on the questionnaire are much appreciated.

\section{Conflicts of interest}

The authors have no financial conflicts of interest.

\section{REFERENCES}

1) Busch-Vishniac IJ, West JE, Barnhill C, Hunter T, Orellana D, Chivukula R. Noise levels in Johns Hopkins hospital. J Acoust Soc Am 2005; 118:3629-45.

2) Park MJ, Yoo JH, Cho BW, Kim KT, Jeong WC, Ha M. Noise in hospital rooms and sleep disturbance in hospitalized medical patients. Environ Health Toxicol 2014;29:e2014006.

3) Darbyshire JL, Young JD. An investigation of sound levels on intensive care units with reference to the WHO guidelines. Crit Care 2013;17:R187.

4) Park M, Kohlrausch A, de Bruijin W, de Jager P, Simons K. Analysis of the soundscape in an intensive care unit based on the annotation of an audio recording. J Acoust Soc Am 2014;135:1875-86.

5) Simons KS, Park M, Kohlrausch A, van den Boogaard M, Pickkers P, de Bruijn W, et al. Noise pollution in the ICU: time to look into the mirror. Crit Care 2014;18:493.

6) Cordova AC, Logishetty K, Fauerbach J, Price LA, Gibson BR, Milner SM. Noise levels in a burn intensive care unit. Burns 2013;39:44-8.

7) Macedo IS, Mateus DC, Costa Ede M, Asprino AC, Lourenço EA. Noise assessment in intensive care units. Braz J Otorhinolaryngol 2009;75:844-6.

8) Qutub HO, El-Said KF. Assessment of ambient noise levels in the intensive care unit of a university hospital. J Family Community Med 2009;16:53-7.

9) Pugh RJ, Jones C, Griffiths RD. The impact of noise in the intensive care unit. In: Vincent JL, editor. Intensive care medicine. Yearbook of intensive care and emergency medicine 2007. Berlin: Springer;2007. p.942-9.

10) Müller-Trapet M, Cheer J, Fazi FM, Darbyshire J, Young JD. Acoustic source localization with microphone arrays for remote noise monitoring in an Intensive Care Unit. Appl Acoust 2018;139:93-100.

11) MacKenzie DJ, Galbrun L. Noise levels and noise sources in acute care hospital wards. Build Serv Eng Res T 2007;28:117-31.

12) White BL, Zomorodi M. Perceived and actual noise levels in critical care units. Intensive Crit Care Nurs 2017;38:18-23.

13) Andrade KP, de Oliveira LL, de Paiva Souze R, de Matos IM. Noise level measurement and its effects on hospital employees based on complaint reports. Rev CEFAC 2016;18:1379-88.

14) Orellana D, Busch-Vishniac IJ, West JE. Noise in the adult emergency department of Johns Hopkins hospital. J Acoust Soc Am 2007;121: 1996-9.

15) Filus W, Lacerda AB, Albizu E. Ambient noise in emergency rooms and its health hazards. Int Arch Otorhinolaryngol 2015;19:205-9.

16) Buelow M. Noise level measurements in four Phoenix emergency departments. J Emerg Nurs 2001;27:23-6.

17) Short AE, Short KT, Holdgate A, Ahern N, Morris J. Noise levels in an Australian emergency department. Australas Emerg Nurs J 2011; 14:26-31.

18) Hasfeldt D, Laerkner E, Birkelund R. Noise in the operating room-what do we know? A review of the literature. J Perianesth Nurs 2010; 25:380-6.

19) Pereira BM, Pereira AM, Correia Cdos S, Marttos AC Jr, Fiorelli RK, Fraga GP. Interruptions and distractions in the trauma operating room: understanding the threat of human error. Rev Col Bras Cir 2011; 38:292-8.

20) Katz JD, Noise in the operating room. Anesthesiology 2014;121: 894-8.

21) Shapiro RA, Berland T. Noise in the operating room. N Engl J Med 1972;287:1236-8

22) Hodge B, Thompson JF. Noise pollution in the operating theatre. Lancet 1990; 335:891-4.

23) Fritsch MH, Chacko CE, Patterson EB. Operating room sound level hazards for patients and physicians. Otol Neurotol 2010;31:715-21.

24) Kylén P, Arlinger S. Drill-generated noise levels in ear surgery. Acta Otolaryngol 1976;82:402-9.

25) Berglund B, Lindvall T, Schwela DH. Guidelines for community noise. Geneva: World Health Organization;1999.

26) Trafik-, Bygge- og Boligstyrelsen., Danish Building regulation BR 18. [serial online] 2017 Dec [cited 2019 Mar 14]. Availble from: URL: http://www.retsinformation.dk/forms/R0710.aspx?id=196435.

27) Wiese $\mathrm{CH}$. Investigation of patient perception of hospital noise and sound level measurements: before, during, and after renovations of a hospital wing. [dissertation]. Lincoln: Nebraska Univ.;2010.

28) Luets A, Weiss B, Penzel T, Fietze I, Glos M, Wernecke KD, et al. Feasibility of noise reduction by a modification in ICU environment. Physiol Meas 2016;37:1041-55.

29) International Organization for Standardization, ISO/TC 43/SC2 Building acoustics. Acoustics: Measurement of room acoustic parameters. Part 2: Reverberation time in ordinary rooms (ISO 3382-2:2008). Geneva: International Organization for Standardization;2008. p.1-17.

30) Hoffman IØ, Zapata Rodriguez V, Jeong CH, Beldam MB, Harte JM. Analysis of room acoustics in Danish Hospitals. Proceedings of Baltic-Nordic Acoustics Meeting 2018; 2018, April 15-18: Reykjavík, Iceland. 